Check for updates

Cite this: RSC Adv., 2019, 9, 7043

Received 13th November 2018

Accepted 9th February 2019

DOI: $10.1039 / c 8 r a 09374 a$

rsc.li/rsc-advances

\section{A comparison of the characteristics of polyurethane-based sealers including various antimicrobial agents}

\author{
Jian Wang, (D) Quanjing Mei, Lili Lin, Fuhua Sun, Jidong Li, Qin Zou, Yi Zuo (D)* \\ and Yubao Li*
}

An obturation biomaterial that possess inherent antibacterial activity has been developed to create a tight seal for the root canal space in treatment. Novel castor oil-based polyurethane sealers composited with different proportions of silver phosphate or zinc oxide nanoparticles were synthesized to investigate the physicochemical properties, antibacterial effect on Enterococcus faecalis, and cytotoxicity on murine fibroblasts compared with commercially available products. The results showed that the physical properties of all of the polyurethane sealers could meet with the standards expected. The microdilatancy character of the polyurethane sealers was particularly preferable for the three dimensional obturation of root canal space. Compared with the silver-loaded polyurethane series, the zinc-loaded polyurethane series showed better antibacterial properties based on the contact mode. Analysis of the kinetics indicated that the setting process of the polyurethane sealers supported a first-order reaction and the setting process was highly effective, with more than $90 \%$ of the isocyanate groups participating in the setting reaction within $12 \mathrm{~h}$. This is beneficial for the rapid consumption of monomers, efficiently avoiding inflammation. The in vitro results showed that the polyurethane sealers loaded with zinc oxide nanoparticles or $1 \mathrm{wt} \%$ silver phosphate were desirable for cell attachment and proliferation compared with the commercial sealers. In conclusion, the castor oil-based polyurethane-zinc sealers, especially PU-Zn5, present good physicochemical and antibacterial properties and cytocompatibility, and could be a promising candidate for application in the field of root canal treatment.

\section{Introduction}

Apical periodontitis is an inflammatory reaction of the periapical tissues and results in the root canal system becoming affected by microbes. ${ }^{1}$ Consequently, the development of root filling materials should be targeted towards improvements in the ability and efficacy of materials allowing dentists to eliminate infections and prevent re-infection. Different formulations of root canal filling materials are available. ${ }^{2}$ Obturation biomaterials have been introduced over the past decade to improve sealing of the root canal system. ${ }^{3}$ However, incomplete filling of the root canal is a major factor in endodontic failure. Subsequent leakage of obturation materials from the periradicular tissues or oral cavity limits the filled efficiency of the canal space. Even if there is no leakage, as little as $1 \%$ shrinkage of root canal sealers can result in gaps that are large enough for bacteria penetration. ${ }^{4}$ The tight seal of these structures is essential to preventing the ingress of bacteria and toxins from the root-canal system into the periradicular tissues after the cleaning and shaping of root canals.

Research Center for Nano Biomaterials, Analytical \& Testing Center, Sichuan University, Chengdu 610064, P. R. China.E-mail: zoae@vip.sina.com; nic7504@scu. edu.cn; Fax: +8628 85418178; Tel: +862885418178
Along the same lines of thought, a small puff of sealer extending through the apical canals has been considered to optimally obturate the canal space. An ideal endodontic sealer is expected to create a hermetic three dimensional (3D) obturation of the entire length of the root canal space, which may contribute to the cut off of communication between the oral environment and periapical tissue., ${ }^{5,6}$ However, most endodontic cement sealers suffer from volumetric shrinkage during setting, ${ }^{7}$ leaving microscopic gaps that potentially serve as pathways for leakage and mostly lead to the failure of root canal treatment owing to bacterial re-infection. ${ }^{8}$

Polyurethane (PU) biomaterials have been widely studied and applied in the biomedical field owing to their desirable mechanical properties, good biocompatibility and tunable chemical structures. ${ }^{9}$ Recently, we prepared injectable PU compounds with a high conversion degree and dilatant characteristic after setting. ${ }^{10}$ The dilatant PU can form a monoblock seal for obturation which could overcome the inevitable microleakage from the combination treatment with guttapercha (GP) and zinc oxide eugenol (ZOE) sealers, the standard obturating materials used in root canal treatment. ${ }^{11}$ However, the dimensional change of the PU sealer allowed expansion up to $2 \%$, which could induce radical pressure on the pulpal aspect and cause a root fracture in deep and narrow root 
canals. PU is a segmented polymer and has a block structure and material characteristics which can be designed and synthesized by changing the composition and ratio of soft and hard segments. ${ }^{12}$ Novel injectable PU is designed to have an appropriate expansion by controlling the soft and hard segments to allow successful endodontic treatment.

Furthermore, as PU materials have no natural antimicrobial activity, antibacterial agents should be considered in the preparation of root canal sealers to suppress the proliferation of microorganisms in the root canal system, even after rigid intracanal irrigation and mechanical preparation. ${ }^{\mathbf{1 3}}$ At present, clinically available root canal fillings, such as Epiphany SE sealer (Resin-based sealer), Pulp canal sealer EWT (Eugenolbased sealers) and EndoSequence BC sealer (Bioceramic sealer), have been endowed with certain antibacterial effects. However, their antimicrobial effects extend for barely one week after use. ${ }^{\mathbf{1 4}}$

Silver-containing systems have been used as disinfectants for several millennia. They possess a very high activity against a broad range of microbes and parasites, even when low doses are used. ${ }^{15}$ As the nature of the silver-cell interaction is dependent on the type of silver species that are present in solution, an antibacterial action based on the surface mode is preferred for use in the fluid-deficient environment of the root canal. Zinc oxide is known as a inorganic antibacterial agent and zinc oxide nanoparticles (ZnO NPs) exhibit appealing antibacterial properties owing to their increased specific surface area as their reduced particle size leads to an enhanced particle surface reactivity. ${ }^{16}$ Therefore, we incorporated different antibacterial modes, such as $\mathrm{ZnO}$ NPs and $\mathrm{Ag}_{3} \mathrm{PO}_{4}$ particles, into the PU matrix to create a novel PU sealer with a long-term antimicrobial effect.

Correspondingly, an injectable system based on a novel PU composition has been designed and antibacterial agents with different modes of action have been added for use in the filling of root canals, respectively. Firstly, a modified castor oil was used as a soft segment to synthesize the injectable PU polymer, and the physicochemical properties were tested according to the clinical requirements necessary for root canal treatment. Secondly, the setting process and curing mechanism of the PU sealers was investigated in detail to extrapolate the monomer conversion and the kinetics of the polymerization process. Finally, the antimicrobial effect and cytotoxicity were evaluated according to the additive concentration of $\mathrm{Ag}_{3} \mathrm{PO}_{4}$ or $\mathrm{ZnO}$ NPs compared with two commercially available products.

\section{Materials and methods}

Castor oil (CO), isophorone diisocyanate (IPDI), zinc oxide nanoparticles ( $\mathrm{ZnO} \mathrm{NPs})$, silver phosphate $\left(\mathrm{Ag}_{3} \mathrm{PO}_{4}\right)$, triethanolamine, stannous octoate, 1,4-butanediol (BDO) and glycerol were purchased from Aladdin Co. Ltd. in Shanghai, China. The diameter of the uniform $\mathrm{ZnO}$ nanoparticles was approximately $30 \mathrm{~nm}$. CO and BDO were dehydrated under decompression with a vacuum of $0.02 \mathrm{MPa}$ at $120{ }^{\circ} \mathrm{C}$ for 3 hours.

\subsection{Preparation of monoglycerides of castor oil}

The monoglycerides of castor oil (MsCO) were prepared by transesterification of glycerol with CO. Briefly, glycerol and CO were put into a dry three-neck flask at a molar ratio of $3: 1$. Calcium oxide $(0.05 \mathrm{wt} \%)$ was used as a catalyst. The reaction mixture was then stirred and heated to $200{ }^{\circ} \mathrm{C}$ for 1 hour under a nitrogen atmosphere to obtain the $\mathrm{MsCO}$ and the hydroxyl value was measured according to the Chinese standards specified in SN/T 0801.20-1999.

\subsection{Synthesis of PU polymer}

2.2.1 PU prepolymer. The pre-dried MsCO and IPDI were charged into a three-neck flask equipped with a nitrogen inlet/ outlet, a thermometer and a magnetic stirrer at a molar ratio of $1: 1.75$ (hydroxyl/isocyanate). The flask was heated to $60{ }^{\circ} \mathrm{C}$ for $4 \mathrm{~h}$ under $\mathrm{a} \mathrm{N}_{2}$ atmosphere, and a small amount of BDO (1/10 of IPDI) as a chain extender was added to the reaction system for $1 \mathrm{~h}$ to produce the isocyanate (NCO)-terminated PU prepolymer (pre-PPU). The number average molecular weight and polydispersity of the pre-PPU were 6275 and 1.49 respectively, which were tested using gel permeation chromatography (GPC, Waters 1525, USA). For composites, the inorganic antibacterial agent $\left(\mathrm{Ag}_{3} \mathrm{PO}_{4}\right.$ or $\left.\mathrm{ZnO} \mathrm{NPs}\right)$ was added to the pre-PPU, and the mixture was stirred for $4 \mathrm{~h}$ at $25{ }^{\circ} \mathrm{C}$ under a $\mathrm{N}_{2}$ atmosphere.

2.2.2 Catalyst B. The triethanolamine was used as a crosslinking agent. Stannous octoate was used as a catalyst in the polymerization process. The above pre-dried agents were mixed in a mass ratio of $2: 1$ and served as catalyst $B$.

2.2.3 PU polymeric sealer. The ultimate PU polymeric sealer was prepared by mixing the pre-PPU with catalyst B in a mass ratio of $10: 1$. The freshly prepared PU sealer was a viscous liquid and presented injectable properties. The sealer cured slowly for several hours demonstrating an increase in the crossing degree and viscosity. Finally, the PU sealer cured as a solid. A total of seven PU groups were prepared. The first three PU composite groups were prepared by varying the content of $\mathrm{Ag}_{3} \mathrm{PO}_{4}$ (1, 3 and 5 wt\%, namely PU-Ag1, PU-Ag3 and PU-Ag5) and the other three groups were prepared by incorporating different contents of ZnO NPs (1, 3 and 5 wt\%, namely PU-Zn1, PU-Zn3 and PU-Zn5). The last group was pure PU (PPU) without addition of $\mathrm{Ag}_{3} \mathrm{PO}_{4}$ or $\mathrm{ZnO}$ NPs. The commercialized endodontic sealers, Apexit Plus and AH Plus, were used as control groups and used in accordance with the manufacturer's instructions.

\subsection{Characterization of physical properties}

Evaluation of the physical properties (dimensional change, solubility, flow and setting time) of the polyurethane sealers was carried out in accordance with the International Organization for Standardization 6876:2001(E). The details of the materials are summarized in Table 1.

\subsection{Mechanical testing}

Teflon molds $(\varnothing 6 \mathrm{~mm} \times 10 \mathrm{~mm})$ were used to prepare all samples for testing of the mechanical properties. The 
Table 1 Sealers used in the study, the manufacturers and compositions

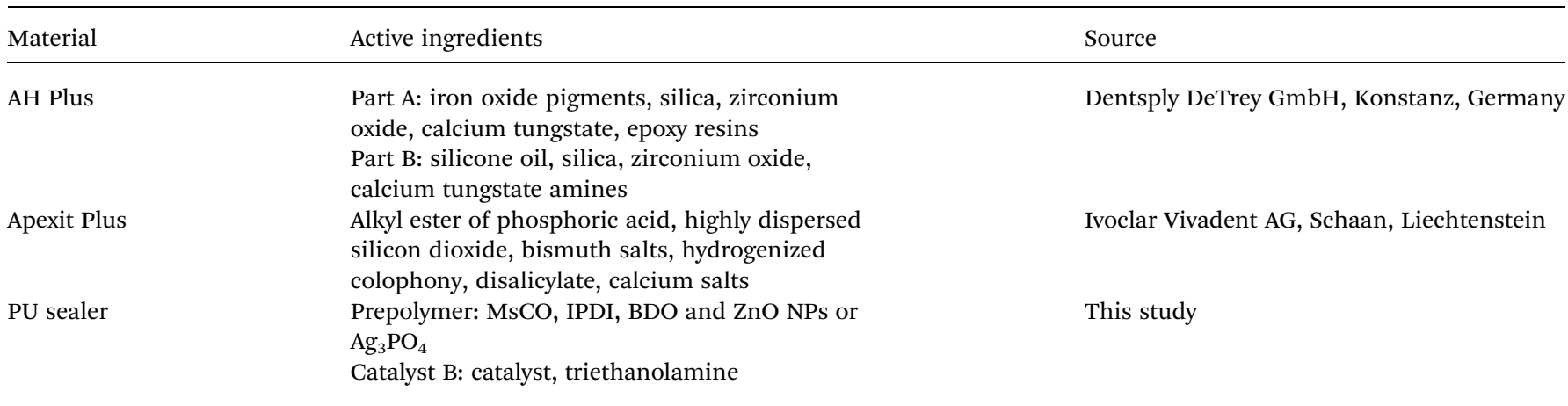

compressive modulus and strength of the sealers were measured using a universal testing machine (AG-10TA, Shimadzu, Japan) at a loading rate of $1 \mathrm{~mm} \mathrm{~min}^{-1}$ until the materials yielded. Each group of sealers was tested three times.

\subsection{Fourier transform infrared analysis}

Fourier transform infrared (FTIR) spectra were collected using a spectrometer (Nicolet ${ }^{\mathrm{TM}}$ 6700, Thermo Fisher Scientific, USA) at the resolution of $2 \mathrm{~cm}^{-1}$ within the wavenumber range of $400-4000 \mathrm{~cm}^{-1}$ to present the chemical groups of reactants and products. The setting process of PPU was measured by monitoring the NCO conversion, which was obtained by calculating the peak area of the NCO groups with the increase in the setting time. It is presumed that no side reactions occur; and that the NCO conversion $(D)$ is equivalent to the setting degree: ${ }^{17}$

$$
\text { Degree of conversion }(D)=1-\frac{N_{t}-N_{\infty}}{N_{0}-N_{\infty}}
$$

Here, $N_{0}$ and $N_{t}$ represent the standardized absorption area of the NCO group at the initial time and at a certain time during the reaction, respectively. In addition, $N_{\infty}$ is the ultimate absorption area of NCO group at the end of the setting process. As all NCO groups from IPDI will be completely consumed during the setting process, the $N_{\infty}$ is 0 .

\subsection{Release of silver ions and zinc ions}

In order to evaluate the release behavior of zinc ions $\left(\mathrm{Zn}^{2+}\right)$ or silver ions $\left(\mathrm{Ag}^{+}\right)$from the $\mathrm{PU}$ sealers with $\mathrm{ZnO}$ or $\mathrm{Ag}_{3} \mathrm{PO}_{4}$, the specimens $(\varnothing 10 \mathrm{~mm} \times 2 \mathrm{~mm})$ were immersed separately in $10 \mathrm{~mL}$ of phosphate-buffered saline solution (PBS) and placed in a water-bath oscillator at $37^{\circ} \mathrm{C}$. After 1, 3, 7 and $15 \mathrm{~d}$, the corresponding solutions were collected to determine the ion concentration of $\mathrm{Zn}^{2+}$ and $\mathrm{Ag}^{+}$using atomic absorption spectroscopy (AAS, iCE3500; Thermo Fisher Scientific, USA). The mean value and standard deviation were calculated for each group of three parallel samples.

\subsection{Examination of material morphology and element distribution}

The morphology of the tested materials was viewed using scanning electron microscopy (SEM, JSM-7500F, Jeol, Japan). In addition, energy dispersive spectrometry (EDS, Jeol 6500LV,
JEOL, Japan) was carried out at random in the area of $\sim 50 \times 50$ $\mu \mathrm{m}$ on the surface of the samples to evaluate the distribution of the $\mathrm{Ag}$ or $\mathrm{Zn}$ elements. Each sample of PU-Ag or PU-Zn was scanned for $60 \mathrm{~s}$. The tested samples were sputter-coated with gold before examination.

\subsection{Assessment of antimicrobial effect}

In total, nine freshly set sealers were used in the tests, including PPU, PU-Ag1, PU-Ag3, PU-Ag5, PU-Zn1, PU-Zn3 and PU-Zn5, as well as AH Plus and Apexit Plus, which were used as controls. All samples $(\varnothing 10 \times 2 \mathrm{~mm})$ were sterilized with ethylene-oxide before the test. The antimicrobial properties of these sealers were measured using the agar diffusion test (ADT), adhesion assay and direct contact test (DCT) by using Enterococcus faecalis (ATCC 29212). For the ADT and DCT, the freshly set samples had also been immersed in $5 \mathrm{~mL}$ of PBS and placed in a waterbath oscillator at $37{ }^{\circ} \mathrm{C}$ for zero, three, seven and 15 days respectively before the two tests.

2.8.1 Agar diffusion test. A $300 \mu \mathrm{L}$ aliquot of bacterial suspension (approximately (3-7) $\times 10^{6}$ colony forming units, CFU mL ${ }^{-1}$ ) was homogeneously spread on the surface of a brain heart infusion (BHI) agar plate. Then the experimental sealers were immersed in PBS for different times and placed on the agar plate. After incubation for $2 \mathrm{~d}$ at $37{ }^{\circ} \mathrm{C}$, the bacterialinhibition zone around the tested sealer was examined in two perpendicular locations, with an accuracy of $2 \mathrm{~mm}$. The size of the inhibition zone $(S)$ was calculated using the following equation:

$$
S=\left(D_{1}-D_{2}\right) / 2
$$

In which $D_{1}$ and $D_{2}$ represent the diameter of the halo and diameter of specimen, respectively. The test was carried out in triplicate and the results were recorded in terms of the average value of the inhibition zone.

2.8.2 Adhesion assay. All of the tested materials were incubated in $2 \mathrm{~mL}$ of bacterial suspension $\left((3-7) \times 10^{5} \mathrm{CFU}\right.$ $\left.\mathrm{mL}^{-1}\right)$ at $37{ }^{\circ} \mathrm{C}$ for $24 \mathrm{~h}$. The culture conditions used were the same as those referred to in previous studies. ${ }^{18,19}$ After incubation, the materials were rinsed with $5 \mathrm{~mL}$ of PBS three times to remove the non-adherent bacteria. After fixation with glutaraldehyde $(2.5 \% \mathrm{v} / \mathrm{v})$, dehydration with gradient ethanol (30$100 \%$ ) and critical point drying, the materials coated with gold 
were viewed using a Jeol 6500LV scanning electron microscope (JEOL, Japan).

2.8.3 Direct contact test. Each specimen was placed at the center of a sterile culture dish, and $20 \mu \mathrm{L}$ of bacterial suspension $\left((3-7) \times 10^{6} \mathrm{CFU} \mathrm{mL}^{-1}\right)$ was dropped onto the surface of the sample. After incubation for 2 hours at $37^{\circ} \mathrm{C}$ in a humid atmosphere, the suspension liquid was evaporated to ensure direct contact between the bacteria and the surface of the tested specimen. Then, the sample surface was rinsed with $3 \mathrm{~mL}$ of PBS three times and the solution was collected. Then $1 \mathrm{~mL}$ of the solution was added to $4 \mathrm{~mL}$ PBS and $300 \mu \mathrm{L}$ of this diluted bacteria suspension was uniformly spread on a BHI agar plate. The number of colonies on the plate was counted after cultivation at $37{ }^{\circ} \mathrm{C}$ for $48 \mathrm{~h}$ and the colony-forming units were obtained for each sample. The dry and sterilized polyethylene film $(\varnothing 10 \mathrm{~mm})$ was used as a control. The bacteriostatic rate was calculated using the following formula:

$$
\text { Bacteriostatic rate }(\%)=\left(C_{1}-C_{2}\right) / C_{1} \times 100 \% \text {; }
$$

In which $C_{1}$ is the colony-forming units of the control group and $C_{2}$ represents the colony-forming units of the tested samples. The mean value and standard deviation were calculated for each group of three parallel samples.

\subsection{Cytotoxicity}

2.9.1 Cell culture. L929 murine fibroblasts purchased from the American type culture collection (ATCC) were incubated in DMEM (Gibco) medium with $10 \%$ fetal calf serum (FBS, Gibco) in a humidified atmosphere with $5 \% \mathrm{CO}_{2}$ in air at $37{ }^{\circ} \mathrm{C}$. The culture medium was replaced every other day, and the cells were subcultured when they reached about $80 \%$ confluence. The samples $(\varnothing 10 \times 2 \mathrm{~mm})$, including PPU, PU-Ag1, PU-Ag3, PUAg5, PU-Zn1, PU-Zn3, PU-Zn5 and the positive control groups (AH Plus and Apexit Plus), were assessed in the following two tests. All tested sealers were sterilized using ethylene oxide gas before use.

2.9.2 Live-dead cell staining assay. Briefly, the L929 cells were seeded onto the surface of the samples $\left((4-6) \times 10^{4}\right.$ cells per sample) in 24-well plates, which were incubated for 1,4 , and $7 \mathrm{~d}$ at $37{ }^{\circ} \mathrm{C}$ in a humid atmosphere of $5 \% \mathrm{CO}_{2}$. The culture medium was refreshed every $2 \mathrm{~d}$. Then, the cell viability was evaluated using a LIVE/DEAD stain (Invitrogen, Thermo Fisher Scientific, USA) according to the instructions of the manufacturer. The stained cells were observed using fluorescent inverted microscopy (Nikon, Tokyo, Japan). The experiment was repeated three times.

2.9.3 Cell viability assay. The cell metabolic activity of the sealers was assessed using a cell counting kit-8 (CCK-8, KeyGEN BioTech, Nanjing, China). L929 cells were seeded onto the sealers in 24 -well plates $\left((4-6) \times 10^{4}\right.$ cells per well), which were cultured for 1,4 , and $7 \mathrm{~d}$ at $37^{\circ} \mathrm{C}$ in a humid atmosphere of $5 \%$ $\mathrm{CO}_{2}$. The culture medium was replaced every $2 \mathrm{~d}$. Subsequently, the CCK-8 was used according to the manufacturer's instructions. The absorbance value for each well was determined by using a microplate reader (PerkinElmer 1420 Multilabel Counter; PerkinElmer, Inc., USA) at $450 \mathrm{~nm}$. Absorbance values

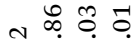

궁

$\mathrm{H}+\mathrm{H}+\mathrm{H}$

तิ ํํำ 눙

完

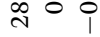

$\stackrel{\infty}{\infty}$

$\begin{array}{llll}\infty & 0 & 0 & 0 \\ H & H & H & H\end{array}$

Љิ

$\underset{-1}{0} \begin{array}{lll}0 & 0 & 0 \\ 0 & 0 & 0 \\ 0\end{array}$

$\mathrm{H} H+\mathrm{H}$

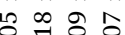

ठृ नें

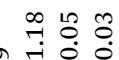

$\mathrm{H}+\mathrm{H}+\mathrm{H}$

$\infty$ 눈 눈 눙

$\begin{array}{lll}1 & 0 & 0 \\ 0 & 0 & 0 \\ 0 & 0 & 0\end{array}$

$\begin{array}{lllll}7 & H & H & H\end{array}$

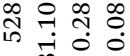

$=\begin{array}{lll}-\infty & 0 & 0 \\ 0 & 0 & 0 \\ 0 & 0 & 0\end{array}$

$\mathrm{H}+\mathrm{H} H$

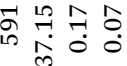

$=\begin{array}{lll}0 & 0 & 0 \\ 0 & 0 & 0 \\ 0 & 0\end{array}$

$\mathrm{H} H+\mathrm{H}$

$\circ \infty 8 \%$

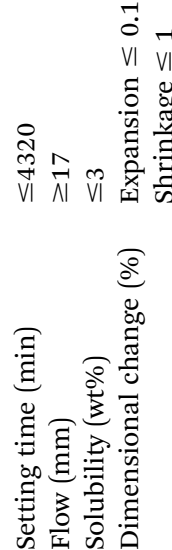


Table 3 Mechanical properties of the PU-based sealers and commercial products ${ }^{a}$

\begin{tabular}{|c|c|c|c|c|c|c|c|c|c|}
\hline \multirow[b]{2}{*}{ Sample } & \multirow{2}{*}{$\begin{array}{l}\text { Pure PU } \\
\text { PPU }\end{array}$} & \multicolumn{3}{|c|}{ Ag-loaded sealers } & \multicolumn{3}{|c|}{ Zn-loaded sealers } & \multicolumn{2}{|c|}{ Commercial sealers } \\
\hline & & PU-Ag1 & PU-Ag3 & PU-Ag:5 & PU-Zn1 & PU-Zn3 & PU-Zn5 & AH Plus & Apexit Plus \\
\hline
\end{tabular}

$\begin{array}{llllllllllllll}\text { Compressive strength }(\mathrm{MPa}) & 0.21 \pm 0.08 * & 0.29 \pm 0.04 & 0.47 \pm 0.11 & 0.66 \pm 0.09 & 0.35 \pm 0.08 & 0.61 \pm 0.10 & 1.14 \pm 0.14 & 0.68 \pm 0.03 & 1.33 \pm 0.18\end{array}$ Compressive modulus (MPa) $3.07 \pm 0.46 * 3.41 \pm 0.28 * 5.88 \pm 0.23 \quad 6.92 \pm 0.34 \quad 4.06 \pm 0.226 .44 \pm 0.53 \quad 9.32 \pm 0.60 \quad 5.67 \pm 0.18 \quad 18.49 \pm 0.77$

$a * P<0.0014$, is significantly different from the Apexit Plus.

were measured in triplicate for each group; the test was performed three times and the plastic well was used as a negative control.

\subsection{Statistical analysis}

The data were expressed as the mean \pm standard deviation (S.D). Statistical analysis was performed via the Kruskal-Wallis test followed by the Mann-Whitney $U$-test with Bonferroni correction using SPSS (version 19.0) software (LEAD Technologies, Inc., Chicago, IL, USA).

\section{Results}

\subsection{Physical and mechanical properties}

The physical properties of the PU sealers and two commercial sealers are summarized in Table 2. The setting time of the PU sealers reduced with an increase in the $\mathrm{Ag}_{3} \mathrm{PO}_{4}$ or $\mathrm{ZnO}$ NPs content, while Apexit Plus and AH Plus showed the shortest and longest setting times, respectively. The PU-Ag sealers had a shorter setting time than that of the PU-Zn sealers using the same proportion of additive. The flow data, indicating the fluid ability of the injectable sealers, of all of the tested sealers were greater than $17 \mathrm{~mm}$, which is the requirement of ISO standard recommendations. The flow of the tested sealers was ranked in the order of PPU $>$ PU-Zn1 > PU-Ag1 $>$ PU-Zn3 $>$ PU-Ag3 $>$ PU-Zn5 $>$ Apexit Plus $>$ AH Plus $>$ PU-Ag5. For the solubility, all values of the tested groups were less than the limitation (3 wt\%, ISO standard). The solubility increased upon addition of $\mathrm{Ag}_{3} \mathrm{PO}_{4}$ or ZnO NPs, and the solubility of the PU-Ag sealers were higher than the PU-Zn series (at the same proportion of additive). In addition, except for PU-Ag5, the two commercial sealers exhibited the highest solubility (PU-Ag5 > Apexit Plus > AH Plus). All PU sealers showed microdilatancy (0.05-0.08\%), which met the ISO standard. However, the AH Plus exhibited slight shrinkage $(-0.05 \pm 0.01 \%)$ and the dimensional change of Apexit Plus was above the standard value $(0.17 \pm 0.09 \%)$. The mechanical properties of the sealers are shown in Table 3. The compressive strength and modulus of PPU was 0.21 and 3.07 $\mathrm{MPa}$, respectively. With an increase in the $\mathrm{Ag}_{3} \mathrm{PO}_{4}$ content of PU-Ag sealers from $1 \%$ to $5 \%$, the values of compressive strength and modulus increased from $0.29 \mathrm{MPa}$ to $0.66 \mathrm{MPa}$ and from 3.41 MPa to 6.92 MPa, respectively. Compared with the PU-Ag series, the margin of increase for the compressive strength and modulus of the PU-Zn sealers grew more rapidly than the PU-Ag sealers at the same added ratio of disinfectants. In contrast, $\mathrm{AH}$ Plus demonstrated similar values of compressive strength and modulus to the PU sealers, but Apexit Plus $(P<0.0014)$ showed the highest data.

\subsection{FTIR spectroscopy}

Fig. $1 \mathrm{a}$ and $\mathrm{b}$ shows that the $\mathrm{C}=\mathrm{O}$ stretching vibration is close to $1751 \mathrm{~cm}^{-1}$, and the $\mathrm{CH}_{2}$, as well as the $\mathrm{CH}_{3}$ absorption peaks occur at about $2926 \mathrm{~cm}^{-1}$ and $2856 \mathrm{~cm}^{-1}$. Specifically, the $\mathrm{OH}$ peak of MsCO (Fig. 1b) at $3377 \mathrm{~cm}^{-1}$ is significantly strengthened compared with CO (Fig. 1a). At the same time, the hydroxyl value raised from 149 of $\mathrm{CO}$ to 267 of $\mathrm{MsCO}$, meaning more $\mathrm{OH}$ groups can be provided by MsCO. The peak intensity of the NCO group of IPDI at $2270 \mathrm{~cm}^{-1}$ decreases after the formation of prePPU, and almost disappears in the PPU sealer (Fig. 1c-e). This indicates that the pre-PPU is an NCO-terminated prepolymer and the NCO groups are almost completely consumed during the setting process.

In order to investigate the setting/polymerization process in detail, a series of infrared spectra of PPU sealers was measured from pre-PPU $(0 \mathrm{~h})$ to PPU sealers at different setting times (1$24 \mathrm{~h}$ ). As shown in Fig. 2a, the peaks at 2856 and $2927 \mathrm{~cm}^{-1}$ are ascribed to the $\mathrm{CH}_{2}$ symmetric and asymmetric stretching vibration. The peak at $1705 \mathrm{~cm}^{-1}$ corresponds to the $\mathrm{C}=\mathrm{O}$ stretching vibration, which is the typical absorption peak for PU. The characteristic peaks around 1532 and $3334 \mathrm{~cm}^{-1}$ belong to the $\mathrm{N}-\mathrm{H}$ deformation and stretching vibration, separately. The absorption peak at $1461 \mathrm{~cm}^{-1}$ is due to the symmetric stretching vibration of $\mathrm{COO}$, and the peak at $1140 \mathrm{~cm}^{-1}$ is from the $\mathrm{C}-\mathrm{O}-\mathrm{C}$ vibration. The $\mathrm{NCO}$ absorption

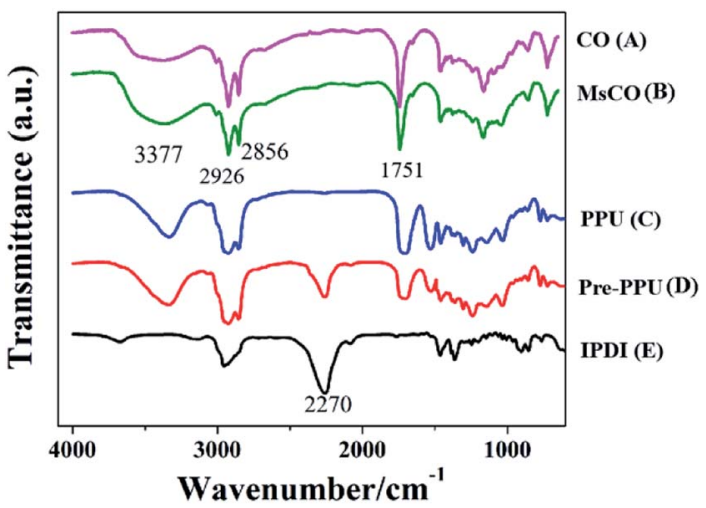

Fig. 1 FTIR spectra of CO (A), MsCO (B), PPU (C), pre-PPU (D), and IPDI (E). The decrease and disappearance of the peak around $2270 \mathrm{~cm}^{-1}(C$ and $\mathrm{D}$ ) indicated the gradual consumption of NCO groups during the polymerization. 

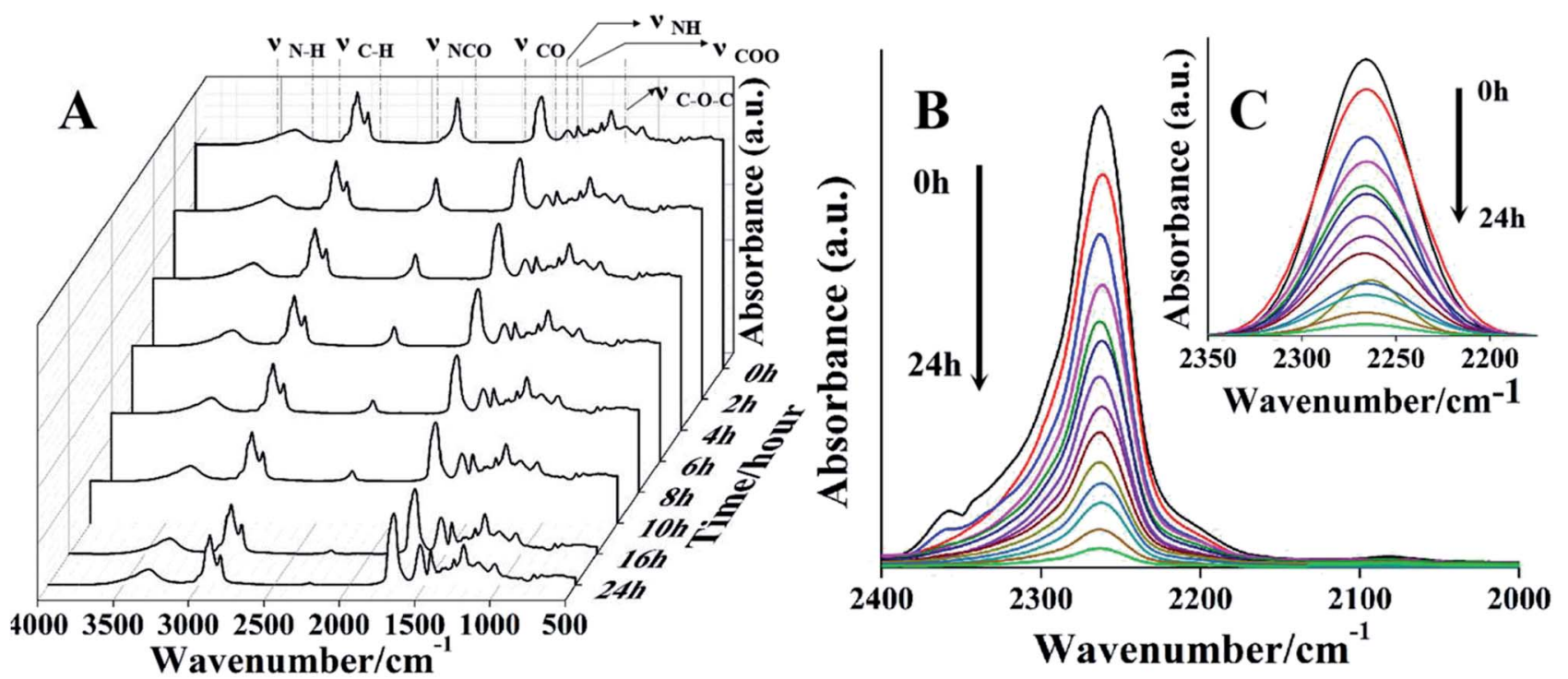

Fig. 2 (A) FTIR spectra of pre-PPU ( $\mathrm{h}$ ) and PPU sealer at different setting times. (B) The decay trend of the NCO groups with setting times of: 0 , $1,2,3,4,5,6,7,8,10,12,14,16,24 \mathrm{~h}$; (C) the curves fitting. The isocyanate decreased as the setting time increased.

band around $2200-2300 \mathrm{~cm}^{-1}$ shows an obvious downtrend owing to its reaction with the $\mathrm{OH}$ and amino groups during the setting/polymerization process. Finally, the NCO groups are almost consumed after $16 \mathrm{~h}$. Meanwhile, the bands at 1600 $1760 \mathrm{~cm}^{-1}, 1532 \mathrm{~cm}^{-1}$ and $1461 \mathrm{~cm}^{-1}$ (attributed to the $\mathrm{C}=\mathrm{O}$, $\mathrm{N}-\mathrm{H}$ and $\mathrm{COO}$ vibration) steadily increase with the setting time.

The decrease of the NCO groups of PPU at different setting times is shown in Fig. 2b. Fig. 2c shows the fitting curves of the isocyanate groups and the integrated peak area of the NCO groups was also measured to assess the conversion rate of NCO groups at different times. With the setting time increasing, the intensity of NCO groups decreases rapidly during polymerization after the first 6 hours. Over $90 \%$ of NCO groups are

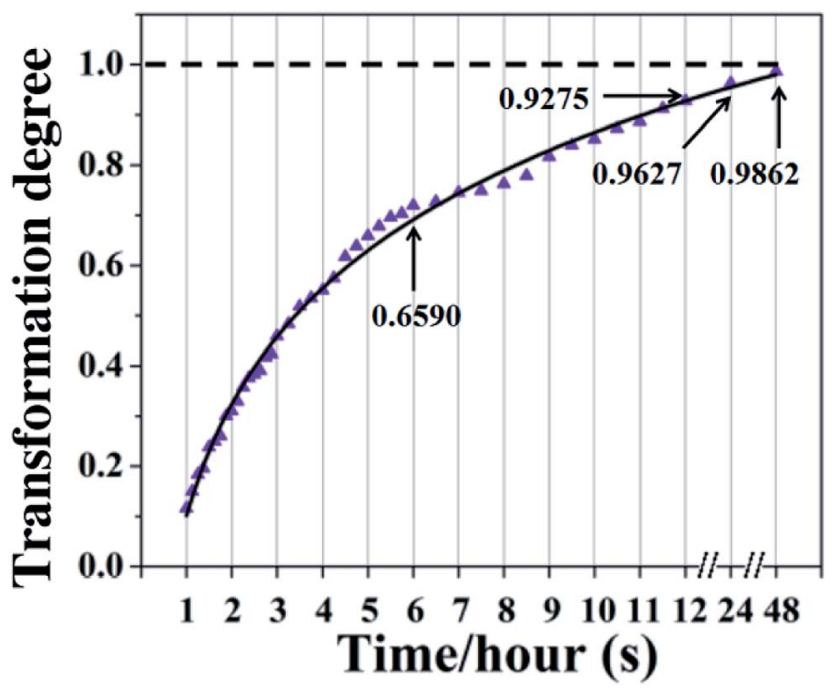

Fig. 3 The conversion/consumption degree of NCO groups during the setting/polymerization process of the PPU sealer with time. A high conversion of $\mathrm{NCO}$ groups can be achieved within 24 hours. consumed within 12 hours, and 96\% conversion can be achieved after 24 hours (Fig. 3).

\subsection{Antibacterial properties}

3.3.1 Agar diffusion test. The inhibition zones of tested samples are illustrated in Fig. 4a-d. The inhibition zone of the PU sealers enlarged as the amount of $\mathrm{Ag}_{3} \mathrm{PO}_{4}$ or $\mathrm{ZnO}$ NPs increased and reduced with the increasing immersion time. The PU-Ag1 and PU-Ag3 $(P<0.05)$ had an antibacterial ability within $3 \mathrm{~d}$ and no antibacterial ability up to $7 \mathrm{~d}$, but the antibacterial activity of PUAg5 $(P<0.05)$ lasted up to $15 \mathrm{~d}$. The antibacterial tendency of PU-Zn1 was similar to PU-Ag1, whereas PU-Zn3 offered antibacterial ability up to $7 \mathrm{~d}$, which was better than PU-Ag3. The antibacterial ability of PU-Ag5 was higher than PU-Zn5 during the first 3 $\mathrm{d}$ and the tendency reversed at 7-15 d. No inhibition zone can be observed in the PPU, AH Plus and Apexit Plus sealers (Fig. 4d). The cumulative release of $\mathrm{Ag}^{+}$or $\mathrm{Zn}^{2+}$ in PBS solution is shown in Fig. 4e. The release of $\mathrm{Ag}^{+}$or $\mathrm{Zn}^{2+}$ increased with the increasing time and the PU-Ag released faster than the PU-Zn series. In order to investigate the distribution of the additive particles in the PU matrix, SEM-EDS was used to observe the surface morphology of the PU composites and the dispersion of the $\mathrm{Ag}$ or $\mathrm{Zn}$ elements on the surface. As shown in Fig. 5a-c and g-i, the surfaces of all of the PU-based sealers were smooth, with no aggregated particles on the surface. In addition, the Ag or Zn elements were homogenously distributed in the PU matrix and the amount increased when more $\mathrm{Ag}$ and $\mathrm{Zn}$ agents were added (Fig. $5 \mathrm{~d}-\mathrm{f}$ and $\mathrm{j}-\mathrm{l}$ ).

3.3.2 Adhesion assay. The adhesion effect of the tested sealers is shown in Fig. 6. Compared with other groups, the bacteria grew and adhered significantly on the surface of PPU (Fig. 6g). The number of bacteria declined when the $\mathrm{Ag}_{3} \mathrm{PO}_{4}$ or ZnO NPs component increased in the PU matrix, and less bacteria can be viewed on the PU-Zn than the PU-Ag groups (using the same proportion of additive, Fig. 6a-f). The 

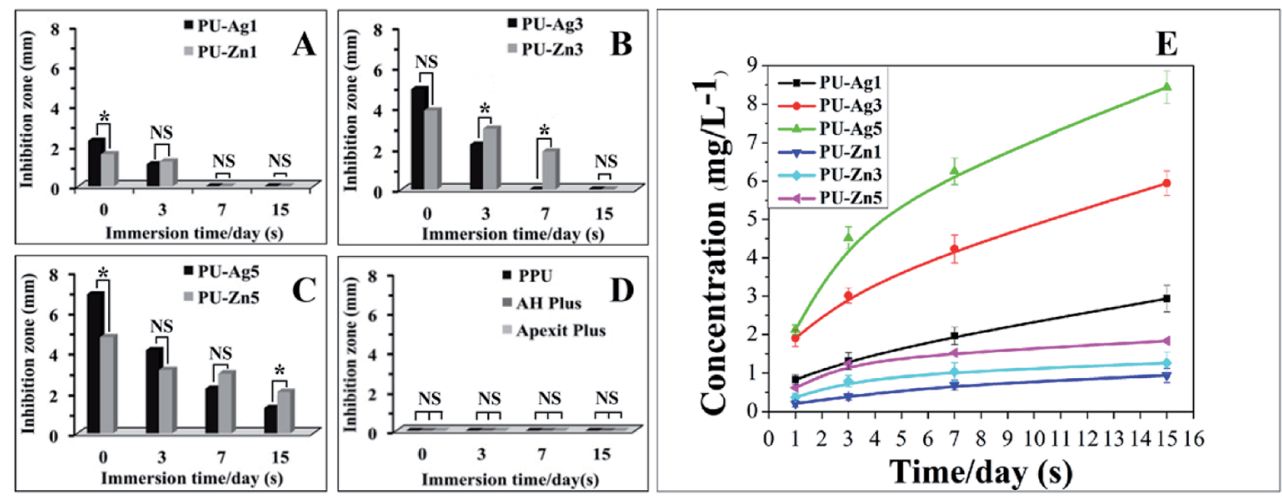

Fig. 4 (A-D) The inhibition zone of the tested sealers against $E$. faecalis after immersion in PBS for $0,3,7$, and $15 d(n=3)$. (A) shows the inhibition zone of PU-Ag1 and PU-Zn1; (B) shows the inhibition zone of PU-Ag3 and PU-Zn3; (C) shows the inhibition zone of PU-Ag5 and Zn5; and (D) shows the inhibition zone of PPU, AH Plus and Apexit Plus. (E) Concentration changes of $\mathrm{Ag}^{+}$or $\mathrm{Zn}^{2+}$ in the PBS solution at different immersion times $(n=3)$. The release rate of $\mathrm{Ag}^{+}$was much faster than that of $\mathrm{Zn}^{2+}$ but PU-Zn5 had a stronger antibacterial effect after immersion for $15 \mathrm{~d}$. Apexit Plus and AH Plus are the commercialized sealers which were used as the control groups. $* P<0.05$ was considered to be statistically significant and NS means no significance.

antibacterial ability of the commercial group (AH Plus $(\mathrm{H})$ and Apexit Plus (I)) was similar to PU-Ag3. Among all of the groups, PU-Zn5 showed the best antiadhesive ability against E. faecalis due to the fewest bacteria being observed on the surface.
3.3.3 Direct contact test. The bacteriostatic rate of the tested sealers is shown in Fig. 7. Except for PPU group, the other samples showed an obvious antimicrobial activity against $E$. faecalis. For the PU-Ag and PU-Zn sealers, their bacteriostatic
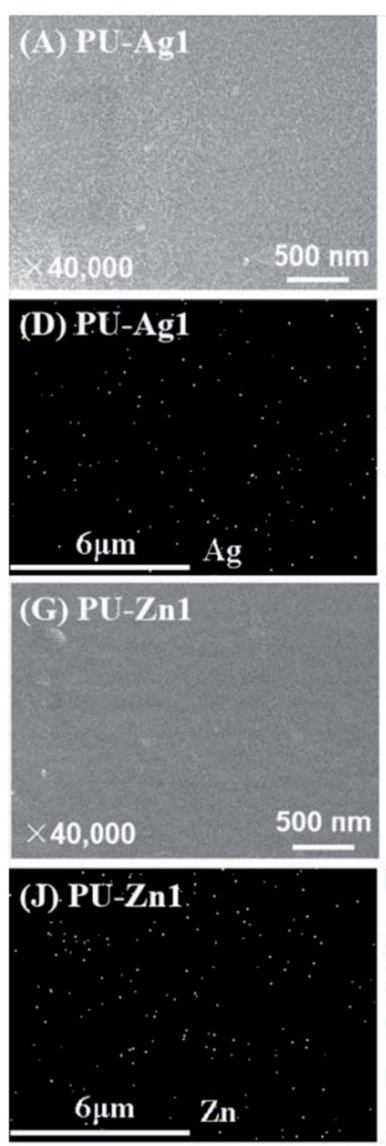
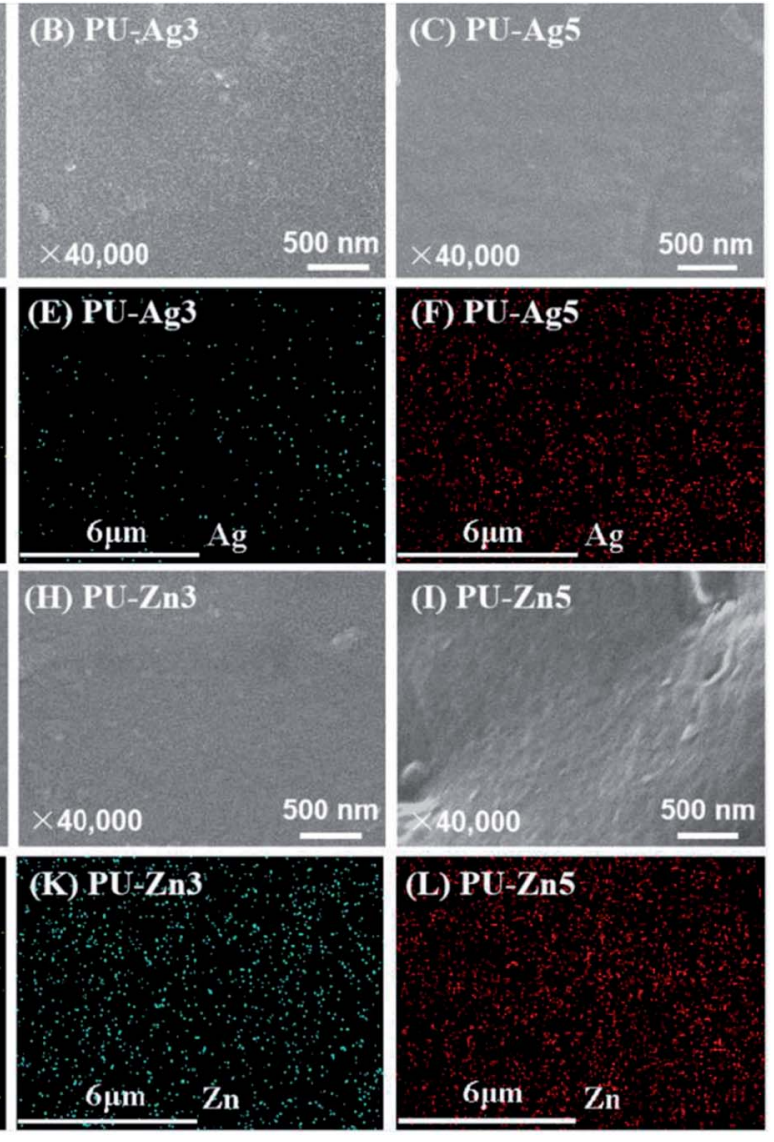

Fig. 5 SEM images of PU-Ag1 (A), PU-Ag3 (B), PU-Ag5 (C), PU-Zn1(G), PU-Zn3 (H) and PU-Zn5 (I); the distribution of Ag or Zn element on the surface of the PU-Ag1 (D), PU-Ag3 (E), PU-Ag5 (F), PU-Zn1 (J), PU-Zn3 (K) and PU-Zn5 (L) sealers. The Ag or Zn element was homogenously distributed in a polymeric matrix and the amounts increased with the addition of more disinfectant. 

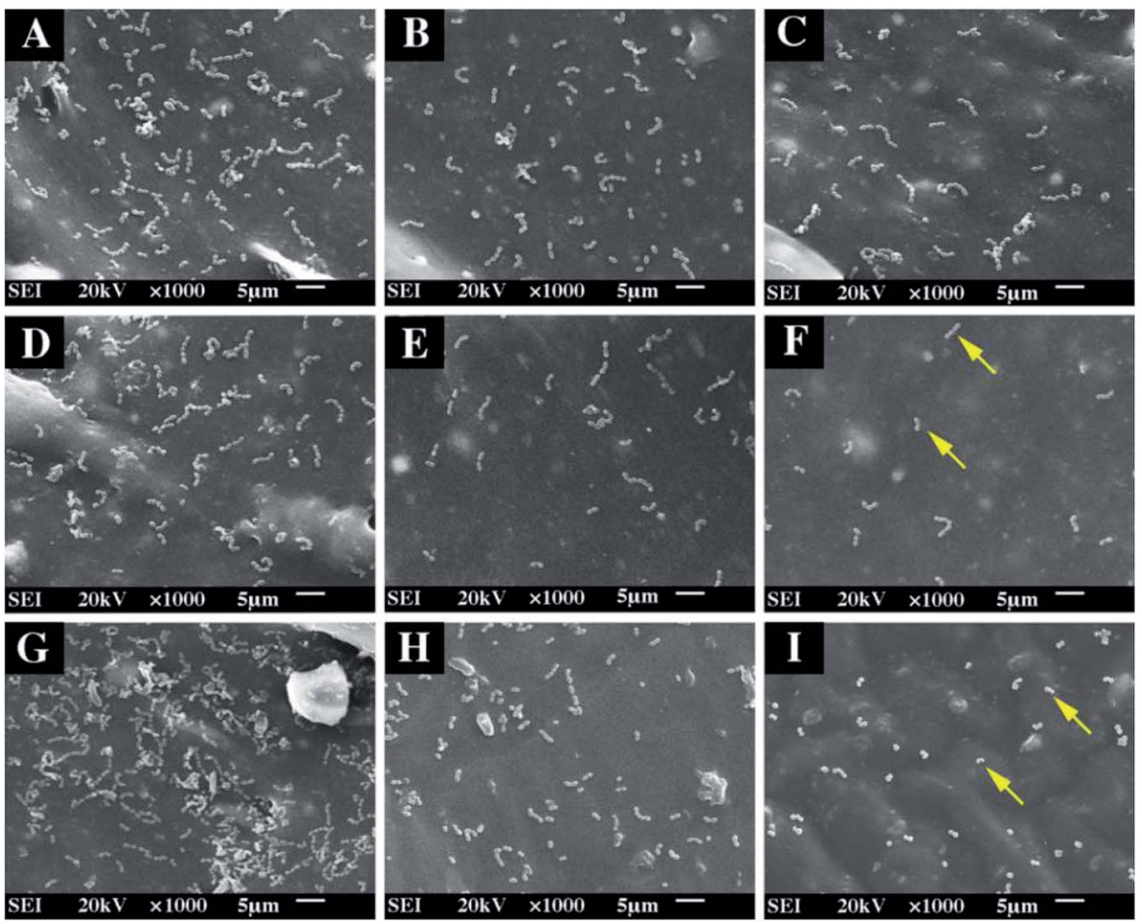

Fig. 6 Bacterial adhesion on tested sealers after incubation for 24 h. (A) PU-Ag1, (B) PU-Ag3, (C) PU-Ag5, (D) PU-Zn1, (E) PU-Zn3, (F) PU-Zn5, (G) $\mathrm{PPU},(\mathrm{H}) \mathrm{AH}$ Plus and (I) Apexit Plus. The bacteria decreased with the increase of $\mathrm{Ag}_{3} \mathrm{PO}_{4}$ or $\mathrm{ZnO}$ content and the yellow arrows show the bacteria.

rate tended to increase with the increased $\mathrm{Ag}_{3} \mathrm{PO}_{4}$ or $\mathrm{ZnO}$ NPs content but decreased with the increase in the immersion time in PBS. The freshly set PU-Ag sealers had a slightly higher bacteriostatic rate than the PU-Zn sealers $(0 \mathrm{~d})$. However, this phenomenon reversed after $3 \mathrm{~d}$, up to $15 \mathrm{~d}$ and the bacteriostatic rate of PU-Ag became weaker than the PU-Zn sealers with
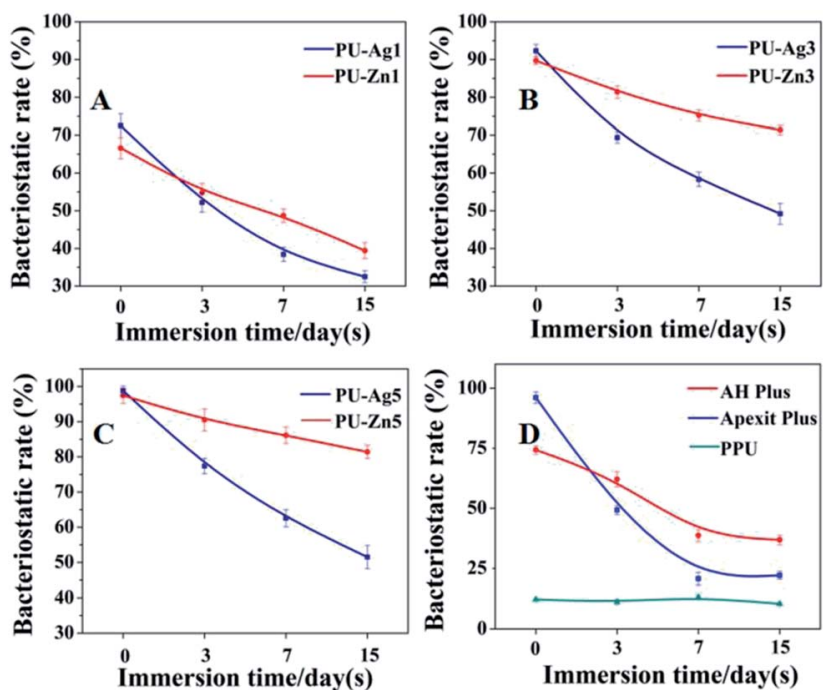

Fig. 7 The bacteriostatic rate of the tested sealers against $E$. faecalis ( $n$ $=3$ ). The PU-Zn sealers showed a better direct antimicrobial activity and a slower reduction than the PU-Ag sealers. Both the AH Plus and the Apexit Plus also had a direct antimicrobial effect which was different from the result found using ADT. a slower reduction of the bacteriostatic degree. It should be noted that both the AH Plus and Apexit Plus, especially when freshly set, also offered antimicrobial effects against $E$. faecalis, which were different from the results obtained using ADT. The freshly set Apexit Plus showed higher bacteriostatic rate than the AH Plus ( $0 \mathrm{~d})$; however, the antibacterial ability of AH Plus surpassed Apexit Plus after immersion in PBS. The antibacterial activity of Apexit Plus and AH Plus dramatically decreased with the increasing immersion time.

\subsection{Cytotoxicity}

The results of the LIVE/DEAD stain are shown in Fig. 8. The green and red cells (marked with white arrows) represent the live and dead cells, respectively. The L929 cells on the surface of the PPU, PU-Zn and PU-Ag1 sealers remained highly viable and only a few dead cells were observed during the incubation period. However, a further increase of the $\mathrm{Ag}_{3} \mathrm{PO}_{4}$ concentration in the PU weakened the viability of cells and the number of dead cells obviously increased for the cells on PU-Ag3, and PU-Ag5 exhibited a spherical morphology which indicates a lack of filopodia extensions. The AH Plus displayed a similar result to the PU-Ag:3 and PU-Ag5. For the Apexit Plus, live spindle shaped cells could barely be observed, with only a few spherical cells and many dead cells adhering to the surface during the culture time.

The cell viability is shown in Fig. 9. Although the absorbance of all groups increased during the culture period, the PU-Zn groups and the PU-Ag1 group were much higher than the PUAg3, PU-Ag5, AH Plus and the Apexit Plus groups from day 1 


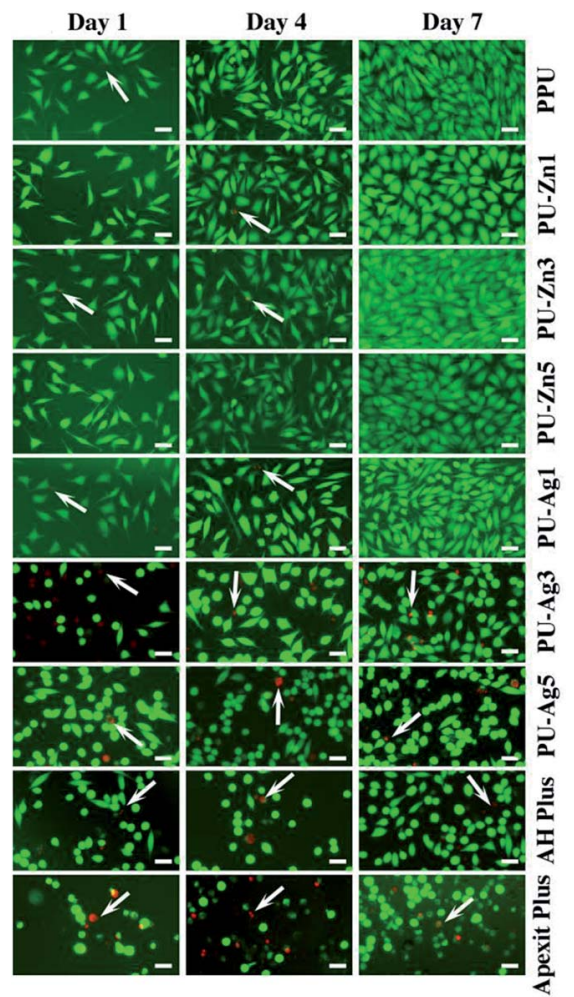

Fig. 8 Fluorescent images of the live/dead staining cells cultured on the sealers for 1, 4 and $7 \mathrm{~d}$. The viable cells (in green) and dead cells (in red, white arrows) were distinguished under the fluorescence microscope. An increase of the $\mathrm{Ag}_{3} \mathrm{PO}_{4}$ concentration resulted in a decreased number of viable cells and more dead cells. Scale bar $=100 \mu \mathrm{m}$.

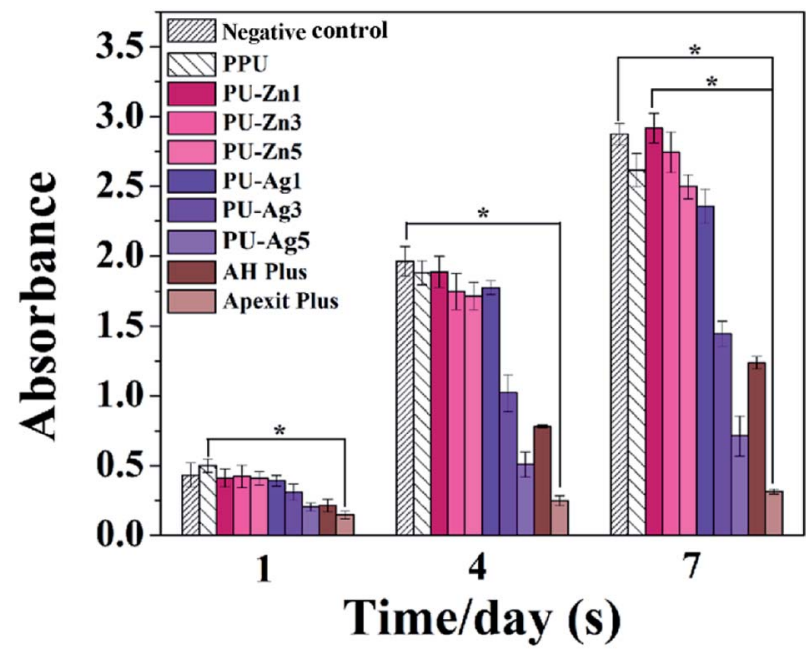

Fig. 9 Cell proliferation histogram after the cells were cultured on the sealers for 1,4 , and $7 \mathrm{~d}(n=3)$. Apexit Plus and AH Plus were used as a positive control and the plastic well was used as a negative control. $* P<0.0011$ was considered statistically significant.

to 7. The cell proliferation of the PU-Ag5 group was lower than the AH Plus group, and the Apexit Plus group $(P<0.0011)$ showed the lowest proliferation. When compared with the control groups, the PPU sealer also showed a high proliferation.

\section{Discussion}

\subsection{Physical and mechanical properties}

The physical properties of root canal sealers, which are mainly determined by the types and proportions of the components, can ensure adequate function under clinical conditions. Therefore, laboratory studies on the physical properties could offer a better understanding of the clinical behavior and the handling performance of endodontic sealers. Although there is no definite standard for the setting time, it should be long enough and in a proper range for clinical operation. However, slow setting time can increase the risk of tissue irritation, with most endodontic sealers releasing toxicity during the setting process. $^{20}$ Compared with the two commercial sealers, the setting time of the PU sealers was appropriate for use in the clinic.

The flow indicates the ability of the root canal sealer to permeate into the accessory, lateral and irregular canals, ${ }^{\mathbf{2 1}}$ and to provide a full seal of the root canal system when materials are used for obturation. ${ }^{22,23}$ The PU-Zn series provided a higher fluidity than the PU-Ag series (the same proportion of additive) and two commercial sealers. This could be attributed to the smaller size and better fluidity of the $\mathrm{ZnO}$ NPs additive than that of the $\mathrm{Ag}_{3} \mathrm{PO}_{4}$ additive in the $\mathrm{PU}$ matrix. However, excessive fluidity could increase the risk of apical extrusion of the sealer. ${ }^{24}$ In terms of permanent treatment, a high solubility, which could irritate and harm periapical tissues, is undesirable for endodontic materials. The PPU had the lowest solubility and the higher solubility of the PU composites was due to the additive of $\mathrm{Ag}_{3} \mathrm{PO}_{4}$ or ZnO NPs. Specifically, the PU-Zn sealers showed a lower solubility than the PU-Ag sealers (using the same proportion of additive) and the two commercial sealers; this could be due to the higher stability of ZnO NPs compared to the $\mathrm{Ag}_{3} \mathrm{PO}_{4}$ in an aqueous environment. The dimensional change indicates the expansion or shrinkage of the endodontic sealer after setting. Except for AH Plus, all of the tested sealers exhibited microdilatancy, which is considered to be desirable in the clinic. Volume shrinkage may lead to microgaps between the root canal walls and the sealer, which allows microorganisms to pass through. ${ }^{25}$ However, excessive expansion is also undesirable, because the extra stress may increase the risk of root fracture, especially in a narrow root canal. Importantly, the expansion rate of all PU sealers met the ISO standard. The physical properties of the PU series shown above testified that the novel PU system could achieve obturation to form a "fluid tight seal", which is essential for the success of the endodontic treatment.

An ideal mechanical property is a prerequisite for the successful clinical application of an endodontic sealer. With the increase of $\mathrm{Ag}_{3} \mathrm{PO}_{4}$ or $\mathrm{ZnO}$ NPs in the PU sealer, the improvement of the compressive strength and modulus could be due to the interfacial interaction between the PU matrix and inorganic particles, which could sustain a greater load and strength. In addition, the PU-Zn series exhibited better mechanical properties, which could be ascribed to the small size of the ZnO NPs, which have a larger contact area than normal $\mathrm{Ag}_{3} \mathrm{PO}_{4}$ particles 
in the polymeric matrix, leading to an improvement in the compressive strength and modulus of the PU sealer.

\subsection{Analysis of setting process}

In this work, injectable PU sealers for root canal filling were designed as a two-part and self-curing system. A prepolymer, viscous liquid with good fluidity, was an NCO-terminated system (pre-PPU), which was prepared using the chemical reaction between MsCO (soft segment) and IPDI (hard segment). The MsCO from renewable castor oil has rich hydroxyl groups and no cytotoxicity. ${ }^{26}$ Therefore, MsCO overcomes the shortcomings of a low hydroxyl value and the reaction efficiency of castor oil. In addition, aliphatic IPDI was selected for the hard segment as the degradation products of the aliphatic polyisocyanate based PU are not carcinogenic or toxic. Catalyst B, as a curing agent, was composed of a catalyst and low molecular weight polyol. When the pre-PPU and catalyst B were mixed in a prescribed proportion, a moderate reaction occurred between the isocyanate groups (from the pre-PPU) and the hydroxyl groups (from the polyols). The setting PU sealer involved the formation of a 3D network through reactions among the polyfunctional groups to form a monoblock for canal obturation. The curing process started from the formation and linear growth of a chain, which soon started to branch and then cross-link. As the curing proceeds, the molecular weight increases rapidly, the molecular size expanded and several chains were linked together into the PU matrix network of infinite molecular weight. Moreover, the efficient conversion in the polymerization may help to reduce the allergic-related reactions and cytotoxicity that are caused by the release of the unreacted monomers during the setting process. $^{27,28}$ On the other hand, the complete conversion could offer more desirable physical properties, such as flexural strength, surface hardness ${ }^{29}$ and formation of a strong bond to dentin. ${ }^{30}$ Therefore, analysis of the kinetics of the polymerization was performed in order to gain a better understanding of the setting process. The conversion rate could be expressed as an equation of the temperature and reaction degree according to the empirical rate laws: ${ }^{31}$

$$
\frac{\mathrm{d} D}{\mathrm{~d} t}=k(T) f(D)
$$

As the polymerization is isothermal, it could also be:

$$
\frac{\mathrm{d} D}{\mathrm{~d} t}=n_{0}(1-D)^{m}
$$

$n_{0}$ is a constant that is correlated with the temperature and $m$, which is the reaction order. $D$ represents the conversion degree obtained using eqn (1).

$$
\begin{aligned}
& \text { when } m=1, \ln (1-D)=-n_{0} t+C \\
& \text { when } m=2,1 /(1-D)=n_{0} t+C \\
& \text { when } m=3,1 /(1-D)^{2}=n_{0} t+C
\end{aligned}
$$

Fig. 10 shows the kinetic curves calculated using the three eqn (6)-(8), and Table 4 summarizes the parameters relating to the setting process of the PU sealer. It is evident that the injectable PU supported a first-order reaction. Namely, the reaction between $\mathrm{OH}$ (from catalyst $\mathrm{B}$ ) and $\mathrm{NCO}$ (from pre-PPU) is a first-order reaction. However, Fig. $10 \mathrm{~b}$ and $\mathrm{c}$ illustrates that both values of $R^{2}$ for the second as well as the third-order reaction are more than 0.9 ; this means that there are probably some other side reactions occurring during the process of polymerization between $\mathrm{NCO}$ and $\mathrm{NH}-\mathrm{CO}$, resulting in the formation of urea bonds and even diureas.

\subsection{Antibacterial properties}

The E. faecalis used in this study is commonly responsible for the etiology of persistent periradicular lesions. ${ }^{32}$ As a Gram-
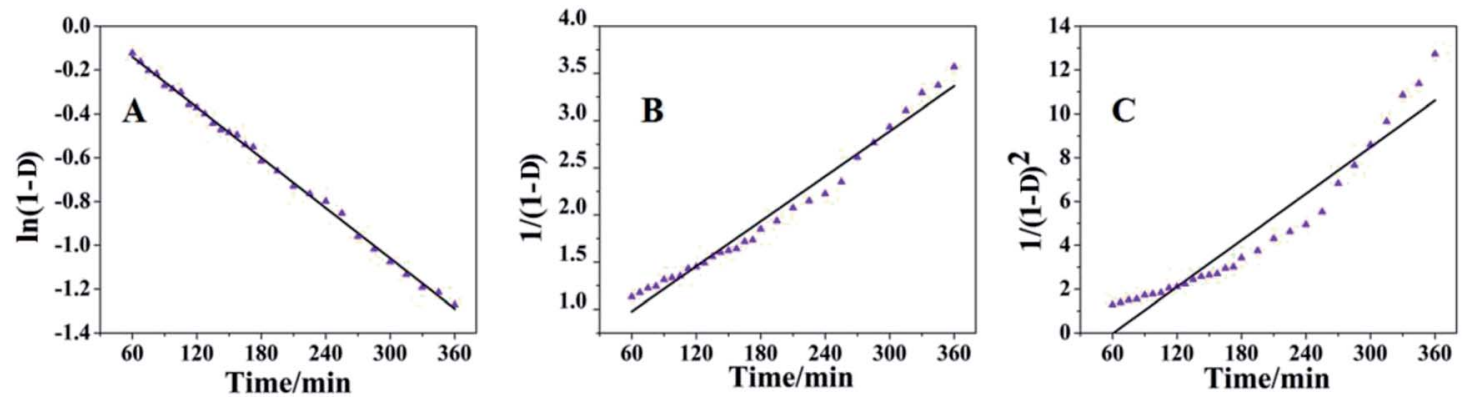

Fig. 10 Kinetic curves of the NCO conversion. (A) $m=1$, (B) $m=2$, and (C) $m=3$.

Table 4 Parameters of the setting/polymerization process of polyurethane materials

\begin{tabular}{lrrrr}
\hline Order/parameters $^{a}$ & \multicolumn{1}{c}{$n_{0}$} & \multicolumn{1}{c}{$R^{2}$} & Er & SD \\
\hline First order & -0.03830 & 0.08986 & 0.99793 & $3.29 \times 10^{-5}$ \\
Second order & 0.00796 & 0.50038 & 0.97604 & 0.00677 \\
Third order & 0.03546 & -2.15522 & 0.91867 & $1.99 \times 10^{-4}$ \\
\end{tabular}

${ }^{a} n_{0}=$ rate constant; $C=$ constant; $R^{2}=$ correlation coefficient; $\mathrm{Er}=$ standard error of rate constants; $\mathrm{SD}=$ standard deviation of the fit. 
positive facultative anaerobic coccoid, E. faecalis is a major cause of endodontic failure after root canal treatment and high percentages (up to 77\%) of bacteria have been found in failed cases. ${ }^{33}$ Studies have reported that after traditional endodontic instrumentation/irrigation treatment with antimicrobial irrigants (sodium hypochlorite $[\mathrm{NaOCl}]$ ), cultivable $E$. faecalis still persist in the almost $40-60 \%$ of canals. ${ }^{34}$ Furthermore, the bacteria can resist the bactericidal effects of intracanal calcium hydroxide $\left[\mathrm{Ca}(\mathrm{OH})_{2}\right]$ dressings for at least $10 \mathrm{~d}$ by maintaining pH homeostasis. ${ }^{35}$ As the results of the anti-microorganism test are related to the experimental technique, test conditions, and even the antibacterial mechanism, different antibacterial assays should be employed to evaluate the antibacterial properties of dental materials. The ADT, adhesion assay and the DCT are popular methods to evaluate the different bactericidal activity modes of biomaterials. ${ }^{36}$

In the $\mathrm{ADT}$, the inhibition zone can be formed on the bacterial lawn around the antimicrobial sample. The freshly set PU-Ag sealers yielded larger inhibition zones than the freshly set PU-Zn sealers $(0 \mathrm{~d})$, and this is because of the stronger diffusion ability of $\mathrm{Ag}^{+}$through the agar (Fig. 4e). However, after being immersed in PBS solution, the PU-Zn sealers displayed a higher antibacterial effect than the PU-Ag sealers owing to the higher concentration of silver ions dissolved into the PBS (Fig. 4e). This suggests that for the PU-Zn sealers loading the antibiotic $\mathrm{ZnO}$ component is better for in situ anti-bacteria treatment than the PU-Ag sealers. In addition, it shows that uniform distribution of the $\mathrm{Ag}_{3} \mathrm{PO}_{4}$ or $\mathrm{ZnO}$ NPs on the surface of the PU sealers is desirable for the long-term release (Fig. 5d-f and j-l). Simultaneously, PPU, AH Plus and Apexit Plus failed to exhibit inhibition zones in the ADT. Actually, the ADT method, depending on the diffusion ability of the antibacterial agent, ${ }^{37}$ is insufficient to evaluate the antimicrobial property and therefore the adhesion assay and DCT method were also used in this study. Similar results are also presented in Fan's investigation on E. faecalis after being cocultured with Ag-loaded mesoporous bioactive glasses. ${ }^{19}$

Adhesion of microorganisms on the surface of an implant is a necessary step for the formation of a biofilm, which may lead to the failure of the function of the implants. ${ }^{38}$ Hence, a material with an excellent anti-adhesion ability can decrease the bacterial colonization and achieve treatment expectations. Compared with PPU, PU-Ag and PU-Zn sealers could inhibit the adhesion of $E$. faecalis on the surface, and the number of bacteria adhering to the sealer surface decreased significantly with an increase in the $\mathrm{Ag}_{3} \mathrm{PO}_{4}$ or $\mathrm{ZnO}$ NPs content. This may be because of the interaction between the material surface and the bacteria, resulting in the disturbance of bacteria charge balance and further serious deformation or death of the bacteria via bacteriolysis. ${ }^{39,40}$ On the other hand, the antiadhesion ability of PU sealers relies on the concentration of antibacterial agent, therefore an adequate antimicrobial agent could offer a good anti-adhesion ability and reduce the risk of re-infection in the process of root canal therapy. In summary, the PU-Zn sealers provided a stronger bactericidal effect via the direct contact between the surface and bacteria.

Interestingly, PU-Ag1 and PU-Zn1 showed no inhibition zones in ADT after 3 d (Fig. 4a), but they suppressed the $E$. faecalis in DCT $(52.2 \%, 54.8 \%$, Fig. 7a). The possible reason for this could be ascribed to the direct contact between the antimicrobial agents and the bacteria in the DCT. In particular, the direct contact process of the PU-Zn sealers effectively and directly inhibited the proliferation of E. faecalis ${ }^{16}$ However, all PU-Ag sealers showed a short-term bacteriostatic rate $(<65 \%$ after $7 \mathrm{~d}$ ). In the study, direct contact between PU-Ag or PU-Zn sealers and the bacteria led to an apparent decrease of the colony-forming units in comparison with the control group. It should be noted that the immersion time, concentration of the antibacterial agent and the antibacterial mode severely affect the antibacterial ability. A longer time interval after immersion in PBS, or a higher loss of the antibacterial component will cause a decrease of the antimicrobial effect. $\mathrm{Ag}^{+}$dissolved in PBS solution in larger numbers in a reduced amount of time when compared to $\mathrm{ZnO}$ particles, and a higher antibacterial component of the PU-Zn sealers is found in the surface area. Moreover, the bactericidal activity mode of $\mathrm{ZnO}$ is the contact inhibition. Therefore, in DCT, the PU-Zn sealers, especially PUZn5, could offer a higher antibacterial activity than PU-Ag sealers after soaking in PBS for 3, 7 and $15 \mathrm{~d}$.

Actually, there are various types of silver disinfectants such as metallic silver, silver nanoparticles and silver salts. Nanosilver systems have presented several advantages since they were first reported in 2004. ${ }^{41}$ Intuitively, the antimicrobial activity of nano-silver has been attributed to the presence of an $\mathrm{Ag}^{0}$ core. After comprehensive studies, $\mathrm{Ag}^{+}$species released from the oxidative dissolution of silver nanoparticles expresses a higher antibacterial activity than $\mathrm{Ag}^{0} \mathrm{NPs}$ when prepared in an inert atmosphere. ${ }^{15} \mathrm{Ag}^{0}$ NPs presents a much lower antibacterial effect when tests are performed in anoxic conditions. ${ }^{\mathbf{4 2}}$ However, $\mathrm{Ag}^{+}$results in a similar bacterial mortality either in anaerobic conditions or in oxidation conditions, even when low doses are used at only a few $\mathrm{mg} \mathrm{mL}^{-1} \cdot{ }^{43}$ As such, the chemical valence state of silver is the key to the irreversible aggregation of the thiol-bearing molecules in the bacterial life-cycle for which the monovalent silver species is the proper antibacterial agent, while the nanoparticles act as a reservoir. ${ }^{44}$ In the narrowly closed environment of the root canal, the $\mathrm{Ag}^{+}$species has an advantage of antibacterial action over $\mathrm{Ag}^{0}$ nanoparticles under a low oxygen concentration. Among these $\mathrm{Ag}^{+}$species, $\mathrm{Ag}_{3} \mathrm{PO}_{4}$ is slightly soluble in water $\left(K_{\mathrm{sp}}=1.4 \times 10^{-16}\right)$ and its solubility is $6.5 \mathrm{mg} \mathrm{L}^{-1}$, higher than $\mathrm{AgCl}$ and $\mathrm{Ag}_{2} \mathrm{~S}^{45}$ The slowly released $\mathrm{Ag}^{+}$ of $\mathrm{Ag}_{3} \mathrm{PO}_{4}$ could inactivate the proteins of bacteria and interfere with the process of DNA replication. ${ }^{46}$ Furthermore, $\mathrm{PO}_{4}{ }^{3-}$ can destroy the normal interconversion cycle of ADP and ATP leading to disturbance of the proliferation of microorganisms. ${ }^{47}$ Therefore, both $\mathrm{Ag}^{+}$ions and phosphate anions have to be introduced into the root canal filling system. Increasing diffusion of PU-Ag contributes to a good antibacterial activity that matches the specific requirements for root canal treatment.

However, it should be considered that the root canal is an environment that is short of liquid and is unfavorable for the release of $\mathrm{Ag}^{+}$. Critically, the dissociated $\mathrm{Ag}^{+}$ions in solution determines the activity of silver-containing disinfection systems. Therefore, the antibacterial ability of PU-Ag1 and PUAg3 faded at $7 \mathrm{~d}$ in the ADT (Fig. 4a and b), even if the $\mathrm{Ag}^{+}$ 
ions are increasingly released from all PU-Ag samples in PBS until $15 \mathrm{~d}$ (Fig. 4e). The higher dose of $\mathrm{Ag}^{+}$in PU-Ag5 could keep on killing bacteria after $7 \mathrm{~d}$ (Fig. 4c), but the toxicity risk of excessively diffusing $\mathrm{Ag}^{+}$ions would give rise to potential health hazards. ${ }^{48}$

Compared to silver, zinc oxide is a bio-safe material that possesses a high bactericidal activity based on distinctive mechanisms, especially direct contact with cell walls resulting in the destruction of the bacterial cell integrity. ${ }^{49}$ Moreover, compared with regular $\mathrm{ZnO}$, ZnO NPs exhibit attractive antimicrobial properties owing to the increased specific surface area as the reduced particle size leads to enhanced particle surface reactivity. ${ }^{16}$ In addition, ZnO NPs can easily pass through the thin peptidoglycan layer of the cell wall (with a thickness of 7-8 nm) to damage the structure of the bacteria. ZnO NPs are reported in several studies as being non-toxic to human cells and few studies suggests that the dissolution of $\mathrm{Zn}^{2+}$ is responsible for the toxicity of ZnO NPs..$^{50}$ Therefore, in order to increase the chance of success of the endodontic treatment, ZnO NPs as another disinfectant has been added into the injectable polyurethane for root canal filling. The $\mathrm{AH}$ Plus and Apexit Plus showed an antibacterial effect in DCT, which contradicted with the ADT, showing no antibacterial effect. The antibacterial ability of AH Plus is possibly due to the antimicrobial effect of formaldehyde,$^{51}$ which is gradually released during the setting process. ${ }^{52}$ Therefore, the antibacterial effect of $\mathrm{AH}$ Plus decreased rapidly and could barely extend to $7 \mathrm{~d}$. The freshly set Apexit Plus had a higher bacteriostatic rate than the freshly sett $\mathrm{AH}$ Plus, but the antibacterial activity of Apexit Plus declined more quickly than AH Plus after immersion in PBS; the reason for this may be due to the rapid release of hydroxide ions from calcium hydroxide, which offers a high $\mathrm{pH}$ value and is relevant to the antimicrobial properties.

\subsection{In vitro cytotoxicity}

For dental resin materials, the conversion degree of monomers varies from $35-77 \%,,^{53,54}$ and the unreacted monomers may lead to cytotoxicity of periapical tissues. ${ }^{27}$ In this work, the tailored PU could achieve a 90\% conversion rate within $12 \mathrm{~h}$. The cell experiments showed that the L929 cells proliferated and survived well on the surface of PPU, PU-Ag1 and all PU-Zn sealers, and the results indicated that these sealers exhibited a good cytocompatibility. However, the PU-Ag3 and PU-Ag5 sealers demonstrated obvious cytotoxicity owing to the high concentration of $\mathrm{Ag}^{+}$ions released from PU-Ag3 and PU-Ag5. It is indicated that an additive amount of ZnO NPs from $1 \mathrm{wt} \%$ to $5 \mathrm{wt} \%$ in the PU sealer is acceptable. However, the addition of $\mathrm{Ag}_{3} \mathrm{PO}_{4}$ in the PU sealer should be below $1 \mathrm{wt} \%$. In conclusion, the PPU and PU-Zn sealers offered a better cytocompatibility than the PU-Ag series and the two commercial sealers. Previous studies have reported that ZOE has long been used as a root canal cement, ${ }^{55}$ and combines with the physical embedding of zinc oxide in a matrix of zinc eugenolate. However, ZOE-based sealers exhibit varying degrees of genotoxicity and cytotoxicity for the release of eugenol. ${ }^{56,57}$ Irritating phenomena have also been observed from gutta-percha, of which zinc oxide is the main component $(60-70 \%)$ of the solid filling materials. ${ }^{58}$ Despite the antimicrobial effect of zinc oxide on facultative bacteria, maxillary sinus aspergillosis has been associated with these zinc-releasing materials such as gutta-percha and ZOE sealers, especially those releasing paraformaldehyde that penetrates the sinus through overfilled sealer and may cause tissue irritation and local necrosis of the sinus mucosa. ${ }^{59} \mathrm{~A}$ larger surface area and lower concentration are accountable for ZnO NPs to balance the antibacterial activity and the biocompatibility for root canal treatment. Compared with these traditional zinc oxide-based sealers, PU-Zn sealers, even at a dose of $5 \mathrm{wt} \% \mathrm{ZnO}$ (PU-Zn5), combine a good antibacterial activity and cytocompatibility.

\section{Conclusions}

This research developed two types of novel injectable, selfcuring and antibacterial PU sealers based on different bactericidal activity modes, that is, PU-Ag and PU-Zn. The novel CObased PU sealers can seal the root apical tightly with a microdilatant monoblock after injection and setting in situ. The mechanism of the curing process was determined using FTIR spectra through investigating the decay of the -NCO groups over time. According to the result, the prepared PU sealer could achieve a high conversion degree in a moderate time, and the curing process of the PU sealer was in accordance with a first-order reaction, which may help diminish the cytotoxicity caused by the residual free monomers. To endow the PU sealers with different antibacterial activities, a series of PU-Ag and PU-Zn sealers with different $\mathrm{Ag}_{3} \mathrm{PO}_{4}$ or $\mathrm{ZnO}$ NPs content values were synthesized. It was shown that all of the PU sealers could meet the requirements of the ISO standard. The antibacterial tests showed that PU-Zn sealers, especially PU-Zn5, displayed a higher steady and prolonged antimicrobial activity than the PU-Ag sealers and the two commercial sealers. The antibacterial action of the PU-Zn, as well as the PU-Ag, sealers were mainly controlled by the contact and diffusion mode. The cell experiment results showed that the PPU, PUAg1 and PU-Zn sealers had good cytocompatibility. In the future, we will study endodontic obturation by in vitro dental experiments and in vivo animal testing to evaluate whether the novel monoblock PU sealers are promising candidates to obtaining a true fluid tight seal.

\section{Conflicts of interest}

There are no conflicts to declare.

\section{Acknowledgements}

This work is supported by the National Key Research and Development Program of China (2017YFC1104303/ 2017YFC1104300). 


\section{Notes and references}

1 M. Torabinejad, W. C. Eby and I. J. Naidorf, J. Endod., 1985, 11, 479-488.

2 P. M. Deshpande and R. R. Naik, Int. J. Appl. Dent. Sci., 2015, 1, 30-34.

3 G. H. Li, L. N. Niu, W. Zhang, M. Olsen, G. De-Deus, A. A. Eid, J. H. Chen, D. H. Pashley and F. R. Tay, Acta Biomater., 2014, 10, 1050-1063.

4 M. Ekambaram, C. K. Y. Yiu and J. P. Matinlinna, Int. J. Adhes. Adhes., 2015, 60, 92-103.

5 M. G. Gandolfi, F. Siboni and C. Prati, Dent. Mater., 2016, 32, e113-e126.

6 H. Zhang, Y. Shen, R. D. Ruse and M. Haapasalo, J. Endod., 2009, 35, 1051-1055.

7 E. S. Pane, J. E. Palamara and H. H. Messer, Dent. Mater., 2012, 28, e150-e159.

8 F. M. Collares, V. C. B. Leitune, F. F. Portella, P. D. Santos, G. D. S. Balbinot, L. A. dos Santos and S. M. W. Samuel, J. Biomed. Mater. Res., Part B, 2018, 106, 1439-1443.

9 K. C. Hung, C. S. Tseng, L. G. Dai and S. H. Hsu, Biomaterials, 2016, 83, 156-168.

10 B. Sun, Y. Zuo, J. Li, L. Wang, K. Tang, D. Huang and Y. Li, Mater. Sci. Eng., C, 2013, 33, 3138-3145.

11 S. Tyagi, P. Mishra and P. Tyagi, European J. Gen. Dent., 2013, 2, 199.

12 S. A. Madbouly and J. U. Otaigbe, Prog. Polym. Sci., 2009, 34, 1283-1332.

13 E. Gjorgievska, S. Apostolska, A. Dimkov, J. W. Nicholson and A. Kaftandzieva, Dent. Mater., 2013, 29, e29-e34.

14 Z. Wang, Y. Shen and M. Haapasalo, Dent. Mater., 2014, 30, e1-e16.

15 B. Le Ouay and F. Stellacci, Nano today, 2015, 10, 339-354.

16 A. Sirelkhatim, S. Mahmud, A. Seeni, N. H. M. Kaus, L. C. Ann, S. K. M. Bakhori and D. Mohamad, Nano-Micro Lett., 2015, 7, 219-242.

17 S. Li, R. Vatanparast and H. Lemmetyinen, Polymer, 2000, 41, 5571-5576.

18 A. H. Sabrah, G. H. Yassen, W. C. Liu, W. S. Goebel, R. L. Gregory and J. A. Platt, Clin. Oral Investig., 2015, 19, 2059-2066.

19 W. Fan, D. Wu, T. Ma and B. Fan, Dent. Mater. J., 2015, 34, 54-60.

20 A. Al-Haddad, C. Ab Aziz and A. Zeti, Int. J. Biomater., 2016, 9753210.

21 M. K. Wu, B. Fan and P. R. Wesselink, J. Endod., 2000, 26, 210-216.

22 V. C. B. Leitune, A. Takimi, F. M. Collares, P. D. Santos, C. Provenzi, C. P. Bergmann and S. M. W. Samuel, Int. Endod. J., 2013, 46, 205-210.

23 M. A. Versiani, J. R. Carvalho-Junior, M. Padilha, S. Lacey, E. A. Pascon and M. D. Sousa-Neto, Int. Endod. J., 2006, 39, 464-471.

24 C. Andolfatto, I. Bonetti-Filho, I. Z. Carlos, J. M. GuerreiroTanomaru, M. C. Kuga, F. B. Tormin and G. Faria, Microsc. Res. Tech., 2017, 80, 1036-1048.
25 M. Brännström and K. J. Nordenvall, J. Dent. Res., 1978, 57, 3-10.

26 N. Teramoto, Y. Saitoh, A. Takahashi and M. Shibata, J. Appl. Polym. Sci., 2010, 115, 3199-3204.

27 M. Goldberg, Clin. Oral Investig., 2008, 12, 1-8.

28 E. P. Heitman and A. P. Joyce, J. Endod., 2008, 34, 186-189.

29 M. Zuber, S. Tabasum, T. Jamil, M. Shahid, R. Hussain, K. S. Feras and K. P. Bhatti, J. Appl. Polym. Sci., 2014, 131.

30 S. Oooka, M. Miyazaki, T. Takamizawa, K. Tsubota, H. Kurokawa and A. Rikuta, J. Oral Sci., 2004, 46, 185-189.

31 L. I. Majoros, B. Dekeyser, R. Hoogenboom, M. W. Fijten, J. Geeraert, N. Haucourt and U. S. Schubert, J. Polym. Sci., Part A: Polym. Chem., 2010, 48, 570-580.

32 C. Poggio, F. Trovati, M. Ceci and M. Colombo, Int. J. Clin. Exp. Dent., 2017, 9, e743.

33 I. N. Rôças, J. F. Siqueira Jr and K. R. Santos, J. Endod., 2004, 30, 315-320.

34 T. Kvist, A. Molander, G. Dahlén and C. Reit, J. Endod., 2004, 30, 572-576.

35 S. H. Siddiqui, K. H. Awan and F. Javed, Photodiagn. Photodyn. Ther., 2013, 10, 632-643.

36 F. Chen, C. Liu and Y. Mao, Acta Biomater., 2010, 6, 31993207.

37 C. R. Sipert, R. P. Hussne, C. K. Nishiyama and S. A. Torres, Int. Endod. J., 2005, 38, 539-543.

38 F. Kara, E. A. Aksoy, S. Calamak, N. Hasirci and S. Aksoy, J. Bioact. Compat. Polym., 2016, 31, 72-90.

39 S. George, S. Pokhrel, T. Xia, B. Gilbert, Z. Ji, M. Schowalter and A. E. Nel, ACS Nano, 2009, 4, 15-29.

40 Y. W. Wang, A. Cao, Y. Jiang, X. Zhang, J. H. Liu, Y. Liu and H. Wang, ACS Appl. Mater. Interfaces, 2014, 6, 2791-2798.

41 I. Sondi and B. Salopek-Sondi, J. Colloid Interface Sci., 2004, 275, 177-182.

42 Z. M. Xiu, Q. B. Zhang, H. L. Puppaia, X. L. Colvin and P. J. Alvarez, Nano Lett., 2012, 12, 4271-4275.

43 H. Xu, F. Qu, H. Xu, W. Lai, Y. A. Wang, Z. P. Aguilar and H. Wei, BioMetals, 2012, 25, 45-53.

44 K. Loza, J. Diendorf, C. Sengstock, L. Ruiz-Gonzalez, J. M. Gonzalez-Calbet, M. Vallet-Regi, M. Köller and M. Epple, J. Mater. Chem. B, 2014, 2, 1634-1643.

45 Z. M. Xiu, Q. B. Zhang, H. L. Puppaia, X. L. Colvin and P. J. Alvarez, Nano Lett., 2012, 12, 4271-4275.

46 Q. L. Feng, J. Wu, G. Q. Chen, F. Z. Cui, T. N. Kim and J. O. Kim, J. Biomed. Mater. Res., 2000, 52, 662-668.

47 M. Heinlaan, A. Ivask, I. Blinova, H. C. Dubourguier and A. Kahru, Chemosphere, 2008, 71, 1308-1316.

48 N. Hadrup and H. R. Lam, Regul. Toxicol. Pharmacol., 2014, 68, 1-7.

49 R. Brayner, R. Ferrari-Iliou, N. Brivois, S. Djediat, M. F. Benedetti and F. Fiévet, Nano Lett., 2006, 6, 866-870.

50 G. Colon, B. C. Ward and T. J. Webster, J. Biomed. Mater. Res., 2006, 78, 595-604.

51 M. Heyder, S. Kranz, A. Völpel, W. Pfister, D. C. Watts, K. D. Jandt and B. W. Sigusch, Dent. Mater., 2013, 29, 542549. 
52 M. R. Leonardo, L. A. B. da Silva, M. Tanomaru Filho and R. S. da Silva, Oral Surg. Oral Med. Oral Pathol. Oral Radiol., 1999, 88, 221-225.

53 J. L. Ferracane, Crit. Rev. Oral Biol. Med., 1995, 6, 302-318.

54 K. Chung and E. H. Greener, J. Oral Rehabil., 1988, 15, 555560.

55 Z. Fuss, O. Charniaque, R. Pilo and E. Weiss, J. Endod., 2000, 26, 519-522.
56 A. V. Nair, M. Nayak, L. K. Prasada, V. Shetty, C. N. V. Kumar and R. R. Nair, J. Contemp. Dent. Pract., 2018, 19, 656-661.

57 F. M. Huang, K. W. Tai, M. Y. Chou and Y. C. Chang, Int. Endod. J., 2002, 35, 153-158.

58 P. M. Desphande and R. R. Naik, Int. J. Appl. Dent. Sci., 2015, 1, 30-34.

59 C. H. J. Hauman and R. M. Love, Int. Endod. J., 2003, 36, 147160. 